\title{
EXTENDING REDUCER/AUGMENTER THEORY INTO THE EMOTION DOMAIN: THE ROLE OF AFFECT IN REGULATING STIMULATION LEVEL
}

\author{
RANDY J. LARSEN ${ }^{1 *}$ and Michael A. ZARATE ${ }^{2}$ \\ ${ }^{1}$ University of Michigan. 580 Union Drive, Ann Arbor, MI 48109-1346 and \\ ${ }^{2}$ University of Texas at El Paso, El Paso, TX 79968, U.S.A.
}

(Received 8 October 1990)

\begin{abstract}
Summary-According to reducer/augmenter theory, augmenters are assumed to react to sensory stimuli with enhanced responsiveness, whereas reducers respond to the same stimuli with dampened responsiveness. Due to their generally understimulated condition, reducers are motivated to seek out stronger or more intense forms of sensory stimulation. When emotion is viewed as a source of stimulation, it becomes plausible to hypothesize that reducers and augmenters may differentially utilize their emotions to modulate stimulation level. Results from Study 1 show that, after a period of boredom, reducers chose more frequently than augmenters to participate in an arousing, emotion-induction experiment, even though they believed the experience would involve the induction of negative affect. Reducers also found the initial boredom-induction task to be significantly more boring and less interesting than the augmenters. Study 2 found that reducers were more likely than augmenters to engage in activities that have a higher probability of evoking emotion in their natural, ongoing lives. Reducers also exhibited episodes of stronger affect and more frequently novelty- and sensation-seeking in their ongoing natural lives than augmenters. Implications of these results for reducer/augmenter theory and for understanding the role of emotion in arousal regulation are discussed, and directions for future research are proposed.
\end{abstract}

The notion that individuals respond differently to the same sensory stimulation is central to reducer/augmenter theory (Petrie, 1967), also known as stimulus intensity modulation theory (Barnes, 1976). An augmenter is someone who amplifies or increases incoming sensory stimulation, whereas a reducer dampens or decreases such sensory stimulation. Reducer/augmenter theory is essentially a theory of self-regulation. The theory suggests that certain individuals (reducers) exhibit a subdued or attenuated response to sensory stimuli. Reducers are consequently stimulationdeprived and seek compensatorily for stronger or more intense forms of stimulation to reach a preferred level of CNS arousal. A demonstration of individual differences in reducing/augmenting can be obtained with the kinesthetic figural aftereffect. In this technique $S$ s judge the width of a wooden block before and after handling a stimulation block. Some $S$ s show an increase in their judgments of the size of the test block after stimulation and are called augmenters, while others show a decrease in their judgments of its size and are called reducers (Herzog \& Weintraub, 1982). This construct refers to the tendency to either amplify or attenuate the perceived effects of sensory stimulation.

Early research illustrated the augmenting/reducing personality effect in the area of pain tolerance. Reducers were found to be more tolerant of pain, presumably because they experience an attenuated response to sensory stimuli (Petrie, Collins \& Solomon, 1958). Other research has focused on individual differences in brain response to sensory stimulation. Results show that the cortical responsiveness of reducers is slower and weaker than augmenters in response to identical levels of sensory stimulation (Buchsbaum, Hair \& Johnson, 1983; Buchsbaum \& Pfefferbaum, 1971; Schooler, Buchsbaum \& Carpenter, 1976). The reducer/augmenter dimension is very general, being found in a wide variety of sensory conditions. For example, during exertion on a cycle ergometer at specific work loads, reducers reported the activity to be significantly less stressful than augmenters, even though there were no differences between the reducers and augmenters in terms of physiological indicators of exertion or fatigue (Robertson, Gillespie, Hiatt \& Rose, 1977). Goldman, Kohn and Hunt (1983) also show the reducer/augmenter difference in absolute auditory threshold.

*To whom all correspondence should be addressed. 


\section{Reducer/augmenter theory}

To explain these effects, many theorists have postulated the existence of a centrally located stimulus intensity modulation mechanism (Baker, Mishara, Kostin \& Parker, 1976, 1979; Petrie, 1967; Silverman, Buchsbaum \& Henkin, 1969; von Knorring \& Johansson, 1980). For some individuals this mechanism reduces or attenuates the subjective intensity of incoming stimuli, whereas for others it augments or amplifies the subjective intensity of such stimuli. Because this mechanism is somewhat like a pre-set 'volume control' device (Baker et al., 1979), individuals must regulate the amount of incoming stimuli in order to achieve and maintain a common desired or optimal range of perceived stimulation (Davis, Cowles \& Kohn, 1983; Sales, 1971; Sales \& Throop, 1972; Zentall \& Zentall, 1983). This theoretical assumption generates specific predictions about the stimulation-seeking behavior of augmenters and reducers, that is reducers (compared to augmenters) should seek out stronger or more intense stimuli in order to compensate for their generally understimulated condition. Augmenters, on the other hand, should seek to avoid stimulation because they are overstimulated to begin with.

This theoretical assumption also generates specific predictions about how reducers and augmenters will experience different levels of environmental stimulation. Reducers should find low-stimulation conditions more boring and adversive than augmenters because they (reducers) are generally understimulated to begin with. Reducers and augmenters are assumed to differentially regulate incoming stimulation because they are differentially reactive to stimulation (Strelau, 1987). Reducers need more stimulation, and augmenters need less, in order to achieve the same desired optimal level of internal, subjective stimulation or arousal. Reducer/augmenter theory shares considerable overlap with other arousal-based personality theories, such as Eysenck's (1967) theory of extraversion, Strelau's (1987) theory of reactivity, and Pavlov's strength of the nervous system theory (e.g. Zuckerman, 1987).

A substantial amount of research has been directed at testing the implications of reducer/ augmenter theory and an early review of the area (Barnes, 1976) concluded that predictions met with relatively good success. For example, reducers were found to exhibit a greater need for stimulation (Sales, Guydosh \& Iacono, 1974), a preference for contact sports (Ryan \& Foster, 1967), and high levels of activity (Petrie, 1967; Sales, 1971). More recent research has shown that reducers exhibit a tendency to work for and consume alcohol (Ludwig, Cain \& Wikler, 1977), abuse illicit stimulant drugs (Deaux, 1976) and consciousness-altering drugs (Kohn, Barnes \& Hoffman, 1979), show a greater desire for social and sensory stimulation (Herzog, Williams Weintraub, 1985; Mishara \& Baker, 1978), and manifest greater social engagement (Mishara \& Baker, 1981).

Research on reduced/augmenter theory has focused almost exclusively on regulating internal, subjective stimulation level via increasing or decreasing objective sensory ar social stimulation. Another possibly powerful, but overlooked, source of stimulation in day-to-day life lies in emotional responses. It may be the case that responses to events that commonly evoke emotion are utilized in much the same manner that objective sensory stimulation is utilized by augmenters and reducers to regulate arousal. When emotional responses are viewed as a form of stimulation then it may be hypothesized that reducers seek out stronger forms of emotional response in order to compensate for their generally understimulated condition. Augmenters, on the other hand, may avoid strong or intense emotional responses in order to keep from aggravating their already overstimulated condition.

\section{The role of emotion in regulating stimulation level}

If emotional responses serve as a source of stimulation then it should be the reducers who seek to maximize the stimulation value of their emotional responses. We are hypothesizing that emotional responses are sources of stimulation that may be utilized by augmenters and reducers in predictable ways to modulate their arousal levels. Emotional responses may function in a regulatory manner by providing the individual with a source of stimulation that can be sought out or avoided in efforts to regulate arousal.

This approach pertains to the behavioral implications of applying reducer/augmenter theory to the domain of emotion. The reducer should seek to behaviorally increase the probability of obtaining strong emotional responses because of his or her chronically understimulated condition. Augmenters should do the opposite. 
From this theoretical position several specific hypotheses emerge. A primary hypothesis is that reducers should find boredom more aversive than augmenters, and that they (reducers) should therefore be more likely to choose emotional stimulation under such conditions. A second hypothesis is that in their natural, day-to-day lives, reducers should exhibit more intense affect, more novelty- and sensation-seeking, and should engage in daily activities that have a higher probability of evoking emotion.

In Study 1 we tested the first hypothesis by creating a laboratory situation of very low stimulation value using a boring and monotonous task. The prediction is that reducers (compared to augmenters) should find the boredom task more aversive, should suffer more performance decrements during a monotonous task, and should be more likely to choose to engage in a task providing strong emotional stimulation after a period of repetitive, monotonous activity.

\section{Study 1}

\section{METHOD}

\section{Subjects}

Participants in this study were 48 college undergraduates. $S$ s came to the laboratory in groups of four. In the laboratory $S \mathrm{~s}$ were seated at individual booths so that they could not see each other's work area. All $S$ s were asked to remove their watches so they would not have any time cues during the boredom induction. $S$ s were instructed not to talk or make any distracting noises and not to get out of their seats during the course of the study. The data from one $S$ had to be discarded because she fell asleep during the boredom induction.

\section{Procedure}

Boredom induction. Ss were each given a packet containing 1584 simple two-digit addition and subtraction problems. They were told that in this phase of the study they would work on these math problems. It was emphasized that they should work at their own pace, whatever was comfortable for them, since we were not interested in speed. It was emphasized that this was not a 'race', that we were not interested in how many problems they could get done, and that they should just work along at a comfortable pace. $S$ s were told that 'every so often' the experimenter would return and ask the $S$ s to circle the problem they were working on. $S$ s began working and the experimenter left the room. Every $5 \mathrm{~min}$ the experimenter returned and asked the $S$ s to circle the problem they were currently working on. This was done so we could assess changes in performance speed over the $35 \mathrm{~min}$ of working on the math problems.

Choice of emotional stimulation. At the end of the $35-\mathrm{min}$ period $S \mathrm{~s}$ were told that we had planned two other experiments for that day. The $S$ s were further led to believe that, since there was not enough time left to run all $S$ s through both experiments, they would have to choose the study in which they would like to participate. The $S$ s were given a description and an informed consent form for each study. They were instructed to read each description and then choose the one study in which they would like to participate. The two studies were described to the $S$ s as follows:

Experiment 1 . In this study you will complete several questionnaires. The questionnaire items concern common, everyday behaviors (e.g. how often you eat breakfast) as well as some personal history questions (e.g. in what part of the country you grew up).

Experiment 2 . In this study you will view a film depicting highly negative, emotional scenes. The purpose of this study is to make you physiologically aroused (i.e. to increase your pulse rate and breathing rate) by inducing a high degree of emotion. Although the experience is somewhat negative, we have found it works fairly well for most $S$ s in terms of making them physically aroused. While you are in this emotional state we will ask you to complete a few items on a questionnaire, and then give you a few minutes to calm down before leaving.

The variable of particular interest in this study is whether or not the $S$ chooses to participate in the emotion induction study, as described above. After collecting the informed consent forms 
on which the $S$ s indicated the experiment in which they wanted to participate, the experimenter asked the $S$ s to complete a few questionnaires.

Questionnaires. One set of questions concerned the $S \mathrm{~s}^{\prime}$ evaluation of the 35-min period of working on the math problems (the boredom induction). We asked: How interesting did you find this task? How difficult did you think the problems were? Taken as a whole, how pleasant was this task for you? Responses were made on a 7-point scale, ranging from $1=$ not at all, to $7=$ quite a bit. $S$ s were also asked if they would be willing to participate in a similar study (requiring repetitive activity) in the near future for another experiment. $S$ s were also asked to estimate the amount of time they worked on the math problems (recall that $S$ s removed their watches prior to starting the experiment).

Form 62 Reducer Index. This questionnaire measure contains 45 items pertaining to potential reducer/augmenter behaviors and experiences. The questionnaire was developed by and is reproduced in Herzog et al. (1985). Sample items are: "I think I would enjoy participating in contact sports", "I am bothered by bright lights (reversed)", "I can stand more pain than most people", and "I think loud noises are unpleasant (reversed)". $S$ s rated how much they agreed that the item applies to them, ranging from 1 (strongly disagree) to 6 (strongly agree). Herzog et al. (1985) report a split-half reliability estimate for Form G2 of 0.61 . The total score was found by Herzog et al. (1985) to be significantly related to the kinesthetic figural aftereffect measure of reducing/ augmenting.

Marlow-Crowne Social Desirability Scale. This scale assesses the extent to which the $S$ projects an overly positive self-image by denying very common but slightly negative personal attributes. The scale is widely used in personality research and is well documented by its authors (Crowne \& Marlow, 1964). We used the social desirability scale in this study to examine whether our substantive variables (e.g. the choice or avoidance of emotional stimulation) are related to socially desirable responding.

After completion of the above questionnaires, $S$ s were told the study was over and that there would not actually be any second experiments. They were given an oral and a written debriefing before leaving.

\section{RESULTS}

The major hypothesis concerns differences between $S$ s who did and did not choose to undergo emotional stimulation (the emotion-induction experiment). It is important to note that the emotion-induction experiment was described to the $S \mathrm{~s}$ as the induction of negative affect; if it had been described as the induction of strong positive affect it is likely that most $S \mathrm{~s}$ would have opted to participate in this experiment. Out of a total of $47 \mathrm{Ss}, 11$ chose to be in the emotion-induction study. Table 1 reports means for $S$ s who chose the emotion-induction experiment and for $S \mathrm{~s}$ who chose the questionnaire study.

$S$ s who chose to undergo the emotion-induction experiment scored significantly more in the reducing direction on the Form G2 Reducer Index than $S$ s who chose the questionnaire study.

Table I. Means and standard deviations for $S \mathrm{~s}$ who chose to be in different experiments

\begin{tabular}{|c|c|c|c|c|c|}
\hline \multirow[b]{2}{*}{ Variable } & \multicolumn{2}{|c|}{$\begin{array}{l}\text { Chose to be in } \\
\text { negative emotion } \\
\text { experiment }\end{array}$} & \multicolumn{2}{|c|}{$\begin{array}{c}\text { Chose to be in } \\
\text { questionnaire } \\
\text { study }\end{array}$} & \multirow[b]{2}{*}{$t$} \\
\hline & Mean & $\mathrm{SD}$ & Mean & SD & \\
\hline $\begin{array}{l}\text { G2 Reducer Index } \\
\text { Social desirability }\end{array}$ & $\begin{array}{r}3.8 \\
13.7\end{array}$ & $\begin{array}{l}0.27 \\
4.75\end{array}$ & $\begin{array}{r}3.5 \\
13.9\end{array}$ & $\begin{array}{l}0.39 \\
4.33\end{array}$ & $\begin{array}{c}-2.33^{*} \\
0.13\end{array}$ \\
\hline $\begin{array}{l}\text { Evaluation of the boredo } \\
\text { How interesting?t } \\
\text { How difficult?t } \\
\text { How pleasant?+ } \\
\text { Willing to do it again?+ } \\
\text { Time estimations }\end{array}$ & $\begin{array}{r}1.3 \\
1.5 \\
1.8 \\
2.4 \\
32.6\end{array}$ & $\begin{array}{l}0.69 \\
0.68 \\
0.75 \\
0.67 \\
9.22\end{array}$ & $\begin{array}{r}2.6 \\
2.0 \\
2.9 \\
1.7 \\
21.4\end{array}$ & $\begin{array}{l}1.10 \\
0.86 \\
1.21 \\
0.85 \\
7.88\end{array}$ & $\begin{array}{r}4.47^{* *} \\
2.01^{*} \\
3.35^{* *} \\
-2.28^{*} \\
-3.63^{* *}\end{array}$ \\
\hline
\end{tabular}

+ Response scale was $1=$ not at all, to $7=$ quite a bit.

${ }_{t}$ Response scale was $I=$ yes, $2=$ undecided, $3=$ no.

$\$$ Estimation of time elapsed during boredom induction, in minutes

$* P<0.05 ; * * P<0.01$ 
Table 2. Pearson correlations between reducing; augmenting and other variables

\begin{tabular}{lc}
\hline & $\begin{array}{c}\text { Form G2 Reducer } \\
\text { Index }\end{array}$ \\
\hline Time estimationt & $0.25^{*}$ \\
Social desirability & 0.04 \\
Evaluation of the boredom induction† & \\
How interesting? & $0.38^{* *}$ \\
How difficult? & 0.01 \\
How pleasant? & -0.11 \\
Willing to do it again? & $-0.27^{*}$ \\
\hline †Estimate of time elapsed during boredom induction, in \\
minutes. \\
†See Table 1 for scoring format for these variables.
\end{tabular}

Also, $S \mathrm{~s}$ who preferred the emotion-induction experience evaluated the prior boredom manipulation as significantly less interesting, less pleasant, less difficult, estimated that more time had elapsed during the boring task, and were significantly more unwilling to repeat the experience than $S \mathrm{~s}$ who chose the questionnaire study. There were no differences between groups in terms of social desirability, suggesting that the choice of emotional stimulation is unrelated to socially desirable responding.

Were the reducers, who are supposedly understimulated to begin with, more affected by the boredom manipulation, as predicted? Table 2 presents the Pearson correlations between the Form G2 Reducer Index and the questionnaire items evaluating the boredom induction procedure. These correlations imply that the monotonous and repetitive activity of working on simple math problems was more aversive to reducers than to augmenters. Reducers reported that the experience took a significantly longer time and was significantly less interesting when compared to the evaluations of the augmenters. Also, compared to augmenters, the reducers were significantly more unwilling to repeat the experience. There was a non-significant correlation between Form G2 and social desirability, suggesting that this measure of reducing/augmenting is not associated with the response bias of socially desirable responding.

In terms of performance, we would expect reducers (compared to augmenters) to show the aversive effects of lowered environmental stimulation more quickly, given their already understimulated condition. One way to examine this prediction is to look at performance changes during the course of the 35-min boredom induction. Reducers should show a decline in performance speed as time on task accumulates. Reducers should either become more underaroused than augmenters or distract themselves somehow to counteract the effects of low stimulation. In either case the performance speed of reducers would decrease over time more than that of augmenters.

To assess decrements in performance speed we subtracted the number of math problems completed during the last $15 \mathrm{~min}$ from the number of problems completed during the first $15 \mathrm{~min}$ of the boredom induction. A high score thus represents a decline in performance speed. The correlation between decline in performance speed and the Form G2 Reducer Index was 0.31 $(P<0.05)$, indicating that reducers completed fewer problems in the later phase of the boredom induction than augmenters. ${ }^{*}$ It is possible that reducers could achieve increased stimulation by adopting a strategy of working harder on the math problems and so this correlation may actually underestimate the effect. Nevertheless, this result is in line with the prediction that the performance of reducers will suffer more than that of augmenters from the effects of boring, repetitive, and monotonous activity.

This study suggests that reducers (relative to augmenters) find boring conditions more aversive and are more negatively affected in their performance under such conditions. We presume that reducers are thus more motivated under such conditions to seek arousal, and that emotions are one source of that arousal. While this study provides some laboratory support for these hypotheses, it would be informative to explore these predictions in the natural, ongoing lives of our $S \mathrm{~s}$. Study 2 was designed to examine differences between reducers and augmenters in terms of their daily

*A $t$-test revealed no differences between reducers and augmenters in terms of the number of problems completed in the first $15 \mathrm{~min}$ of the boredom induction. Thus a high difference score does indicate more of a decline in performance over time than a low difference score. 
emotional lives and the activities that they choose to engage in on a day-by-day basis. We predict that reducers (relative to augmenters) will more frequently engage in daily activities that have a higher potential for evoking emotion, that reducers (relative to augmenters) will have more intense emotions in their ongoing daily lives, and that reducers (relative to augmenters) will engage in more novelty- and sensation-seeking in their day-to-day lives.

\section{Study 2}

\section{METHOD}

\section{Subjects}

Participants in this study were 43 college undergraduates, who were enrolled in a semester-long course on 'Personality Research'. The course was announced through campus advertisements with virtually no constraints on who could participate. As a class project each student was required to complete three 'Daily Mood and Activity Reports' each day for 56 consecutive days (i.e. 8 weeks). $S$ s were instructed to complete a report at noon to describe their morning, another report around 6:00 p.m. to describe their afternoon, and a final report before retiring to summarize their evening. To help ensure compliance, $S$ s were required to turn in completed forms each day, except for weekends when they returned the forms for Friday, Saturday and for Sunday on Monday.

\section{Daily mood and activity report}

The activity section of the daily form contained a list of 24 activities that are available to most college students (e.g. talking on the phone, watching TV, playing team sports, going to a party). On each report form the $S$ was asked to check off each of the 24 activities that he or she engaged in during that reporting period. We then computed a total score for each of the activities for each $S$ over all the reporting occasions. Thus we have an index of the frequency with which each $S$ engaged in each of the 24 activities over a 2-month period of their ongoing, day-to-day lives (e.g. how often each $S$ watched TV, went to parties, talked on the phone, etc.).

This list of activities had been previously scaled for how likely each of them are to provoke emotion. A sample of 556 introductory psychology students rated each activity for 'How likely is it that engaging in this activity will provoke strong emotion in the average college student?' Each activity was rated on a 9-point scale, from 1 (not at all likely) to 9 (extremely likely). These activities were rank ordered by the probability that they would evoke emotion. The five highest and five lowest emotion-provoking activities are as follows. Activities scaled as 'not at all likely to evoke emotion' were: leisure reading, writing letters, watching TV, doing school work, and going shopping. Those activities scaled as 'extremely likely to evoke emotion' were: sexual activity, playing team sports, playing cards/board games, going to a party, and playing video games.

For each $S$ we then computed a total 'Emotion Seeking Activity' score by summing up the number of times they engaged in one of the five high-emotion activities and subtracting from this the number of times they engaged in one of the five low-emotion activities. This score is calculated over 2 months of thrice-daily reporting, and so should be a very reliable measure of the tendency to engage in activities that have a high probability of evoking emotion.

The mood section of the daily mood form contained a list of several mood adjectives which the $S$ s rated by responding to the question "How much of each of the following emotions did you experience during the time period?" Responses were made on a 6-point rating scale, ranging from 1 (not at all) to 6 (extremely much). This rating format and the adjectives on it have been used extensively in prior studies of daily mood (e.g. Diener \& Larsen, 1984; Larsen, 1987; Larsen \& Diener, 1985, 1987). Prior factor analyses of this set of daily mood adjectives suggests the presence of a powerful bi-polar first factor, loading positive affect items (happy, pleasant, joyful, and enjoyment/fun) at one pole, and negative affect items (unhappy, depressed/blue, frustrated, angry/hostile, and worried/anxious) at the other pole.

The average intensity of emotion is computed for each $S$ according to the daily mood intensity scoring system of Larsen and Diener (1987). This is done by first determining, for each measurement occasion, whether more positive affect (PA) or more negative affect (NA) is reported. Then we average over all those occasions wherc morc PA than NA was reported for each $S$. This 
tells how intense the $S$ 's positive affect is, on the average, on those days when he or she is feeling primarily positive. This PA Intensity score (PAINT) tells us how 'high' the $S$ typically goes up when they are 'up'. A similar Negative Affect Intensity score (NAINT) is computed by averaging, for each $S$, over all those occasions where they reported more NA than PA. This tells us how 'low' the $S$ typically goes down when they are 'down'. As discussed in Larsen and Diener (1987) these two intensity scores tend to be highly correlated, suggesting a general intensity dimension to people's emotional lives. People who tend to go up quite high when they are feeling up also tend to go down quite low when they are feeling down. In this sample, PAINT and NAINT were correlated at 0.67 , again suggesting a general intensity dimension. We consequently summed PAINT and NAINT together for each $S$ to index their general Daily Mood Intensity over the 2 months of daily observation.

The daily mood and activity report also contained two additional questions in order to tap into novelty- and arousal-seeking. One question inquired about novelty: "Were the events you engaged in during this time period typical/usual or novel/unusual for you?" Another question inquired about sensation-seeking: "How much did you seek out stimulating things to do during this time period; how much did you try to 'liven up' your day? (e.g. play loud music, etc.)". Ss responded to both questions on a 5-point scale, anchored from 0 (not at all) to 4 (extremely). Total scores on novelty-seeking and sensation-seeking were computed by computing each $S$ 's average daily report on these two questions over the 2 months of observation.

\section{Personality measures}

Form G2 was again used for the assessment of reducing/augmenting. In addition, we included a second questionnaire for the assessment of this dimension, the Vando R/A Scale. Vando (1969) developed this scale to discriminate persons who were high vs low in pain tolerance and for general research on the individual difference dimension of reducing/augmenting. The R/A Scale contains 54 forced-choice items referring to activities with differing levels of stimulation, from which the $S$ indicates his or her preference. Examples of R/A Scale items are: 'see the movie or read the book', 'live in a crowded home or live alone', and 'continuous anesthesia or continuous hallucinations'. Vando (1969) reports a split-half reliability of 0.89 and a test-retest correlation of 0.74 . A recent review of this R/A Scale (Barnes, 1985) highlights convergent and discriminant validity studies of this instrument and concludes that the scale is a valid measure of stimulus reducing/augmenting. Barnes (1985) also provides the complete item set and scoring instructions for the Vando R/A Scale.

\section{RESULTS}

Pearson correlations were computed between all relevant variables. Table 3 provides the triangular correlation matrix between all variables. The two measures of reducing/augmenting converged remarkably well, especially considering that these scales have different response formats, different item content, and were administered over a month apart in this study. Both scales correlated significantly with the emotion-seeking variable computed from the daily activity forms, although Form G2 has much more variance in common with emotion seeking than the Vando R/A Scale. This result supports the main hypothesis that, in their natural, day-to-day lives, reducers seek to engage in those activities that have a higher probability of evoking emotion. This finding can be considered a conceptual replication of Study 1, in that reducers were there found to seek out emotional experiences in a controlled laboratory setting, and in Study 2 reducers were found to seek out emotional experiences in their natural, ongoing lives.

Table 3. Pearson correlations between all variables from Study 2

\begin{tabular}{lccccc}
\hline \multicolumn{5}{c}{ Table 3. Pearson correlations between all variables from Study 2} \\
& $\begin{array}{c}\text { Vando R A } \\
\text { scale }\end{array}$ & $\begin{array}{c}\text { Emotion- } \\
\text { seeking }\end{array}$ & $\begin{array}{c}\text { Novelty- } \\
\text { seeking }\end{array}$ & $\begin{array}{c}\text { Sensation- } \\
\text { seeking }\end{array}$ & $\begin{array}{c}\text { Mood } \\
\text { intensity }\end{array}$ \\
\hline Form G2 & $0.66^{* *}$ & $0.57^{* *}$ & $0.30^{*}$ & $0.34^{* *}$ & $0.26^{*}$ \\
Vando R A & & $0.34^{* *}$ & $0.25^{*}$ & $0.43^{* *}$ & $0.35^{* *}$ \\
Emotion-seeking & & & $0.30^{*}$ & 0.20 & $0.34^{* *}$ \\
Novelty-seeking & & & $0.45^{* *}$ & $0.42^{* *}$ \\
Sensation-seeking & & & & 0.24 \\
\hline${ }^{*}<0.05 ; * * P<0.01$. & & & &
\end{tabular}


Sensory reducing (as measured by both the Form G2 and the Vando R/A scale) also correlated significantly with average daily mood intensity, suggesting that the emotion-seeking behaviors of reducers are at least partially successful. That is, on a day-by-day basis, reducers are experiencing stronger or more intense emotions than augmenters. This is most likely the result of engaging more frequently in those daily activities that have a higher probability of evoking emotion, as indicated above.

The remaining correlations in Table 3 can be interpreted somewhat as validity coefficients. That is, sensory reducing should correlate significantly with novelty- and sensation-seeking. These findings replicate the results of other researchers who have found sensation-seeking and noveltyseeking to covary with sensory reducing (see Barnes, 1985, for a review of this research).

\section{GENERAL DISCUSSION}

The results of Study 1 provide experimental support for the hypothesis that reducers suffer more than augmenters from the effects of low arousal (i.e. report more negative subjective responses to a repetitive and boring task and show greater performance decrements during the boring task). Of primary interest, however, is the finding that reducers (relative to augmenters) are more likely to choose emotional stimulation when they are bored, even if they think the emotion will be negative. Those $S$ s who chose to undergo an emotion-induction experience after the period of boredom had higher reducing scores than those who chose a less arousing experience. Also, reducers found the boredom induction task to be significantly more boring and less interesting, thought the boredom session lasted longer, and were less likely to volunteer for a similar experience, than the augmenters.

In Study 2 we naturalistically assessed the daily activities of 43 college students over a 2 -month period. Each daily activity was scaled by an independent sample for how likely that activity would produce emotion in the average person. Reducers (compared to augmenters) engaged more in those activities with a high probability of producing strong emotional responses (e.g. playing team sports, playing cards/board games, going to a party, playing video games) and engaged less in those activities with a low probability of evoking emotion (e.g. leisure reading, watching television, writing letters) than augmenters.

The pattern of results from these two studies suggests a process whereby reducers and augmenters differentially regulate stimulation input. This process is one of engaging in or avoiding those activities that have a high or low potential for eliciting emotional engagement. This process is not isomorphic with sensation-seeking, however. Rather than referring to the thrilling, unusual, and risky activities sought by the sensation-seeker, we examined fairly mundane and ordinary activities that simply provide a higher probability of evoking emotional involvement. Such activities were available to all $S$ s, but were engaged in more frequently by the reducer $S$ s.

Reducer/augmenter theory has three primary assumptions (Sales et al., 1974). First, individuals differ from each other in the magnitude of their response to sensory stimulation. Consequently, a level of objective stimulation that is perceived by the average person as 'just right' will be 'too little' for the reducer and 'too much' for the augmenter. This assumption implies the existence of a stimulus intensity modulation mechanism that consistently regulates the effects of sensory stimulation (Buchsbaum \& Pfefferbaum, 1971; Sales, 1972). The second assumption of reducer/ augmenter theory is that there is some optimal level of internal stimulation (i.e. arousal). If an individual is internally understimulated then an increase in objective stimulation will be pleasurable and sought out. Conversely, if internal, perceived stimulation is 'too much' a decrease in stimulation will be pleasurable and sought out. This is the motivational assumption from which behavioral implications of the theory are derived. The third assumption of reducer/ augmenter theory is that the level of internal, evoked stimulation that is perceived as optimal tends to be similar across individuals. Thus the individual difference is not in the optimal level per se, but rather in the amount of objective stimulation necessary to reach that level (Geen, 1984). This is a point worth emphasizing, that the personality characteristic of interest is not defined by differences in what is subjectively perceived as an optimal level of stimulation, but rather by differences in the amount of objective stimulation necessary to achieve and maintain that perceived level. 
The present studies suggest not so much a modification of reducer/augmenter theory as an extension of the behavioral implications of that theory into the domain of emotion. Our view is that emotional responses are employed by sensory reducers and augmenters differentially to regulate their internal, perceived level of stimulation. Most researchers would agree that emotional responses are typically associated with increases in CNS arousal. When emotional responses are viewed in terms of CNS stimulation then we might ask if reducers seek out strong emotional responses in order to regulate their arousal level upward. Given the essentially affirmative answer to this question provided by the present studies, future research can focus on more specific hypotheses regarding the processes of arousal compensation via the regulation of emotional and sensory stimulation.

Future research might focus on the potential mechanisms whereby affective responses are created or sought out by the individual needing to increase or decrease his or her internal stimulation level. Researchers might address how the process of seeking out or creating strong emotional responses actually works to satisfy a need for stimulation. Three different approaches to this problem readily come to mind, although no single approach is exclusive of the others. The first approach would take a psychophysiological perspective. For example, certain limbic structures that are involved in the detection of affective significance also play an important role in regulating the activity of the ascending reticular activating system (Derryberry \& Rothbart, 1984; Tucker \& Williamson, 1984). This system in turn plays a role in regulating cortical arousal and reactivity to sensory stimulation. Understanding individual differences in these neurological structures, and the role of these structures in the regulation of arousal and emotion, would be important topics for future research.

A second research perspective would focus on cognition and its role in creating or increasing the stimulation value of emotional responses. It could be that sensory reducers and augmenters have developed cognitive control strategies for either increasing or decreasing the stimulation value of their emotional responses according to their respective needs for stimulation. Certain cognitions may intensify or decrease the magnitude of emotional responses. Studying the kinds of cognitive operations that result in high or low levels of affective response may be a promising line of research on arousal regulation. The details of one such cognitive style are discussed by Shapiro (1965), who refers to it as an hysterical style of cognition. This style is characterized by an incapacity for persistent concentration, a distractive susceptibility to what is immediately striking or obvious, and a focus on nonfactual and impressionistic aspects of the environment (Shapiro, 1965, p. 113). The notion that such a cognitive style is associated with a heightened emotional responsiveness has recently received a degree of empirical support (Dunivin \& Zenhausern, 1981; Larsen, Diener \& Cropanzano, 1987; Tucker \& Williamson, 1984).

A third perspective might focus more directly on behavior per se, in particular on the kinds of activities that result in a greater likelihood of direct proprioceptive stimulation. A thoughtful discussion of the role of activity level in the regulation of CNS arousal is provided by Strelau (1982, 1983). Zentall and Zentall (1983) also discuss the role of activity level in compensating for the trait-like characteristic of being under- or over-stimulated. These perspectives view activity level as a source of proprioceptive stimulation that may function according to reducer/augmenter principles. Another form of activity that has been associated with the regulation of arousal is extraverted behavior (Eysenck, 1967; Eysenck, 1983b). Extraverts are believed to be chronically underaroused and thus compensate by seeking increased stimulation, particularly in the form of social activity. Introverts are overaroused to begin with and hence seek to avoid excess stimulation. Over two decades of research provide general support to this position (for a review see Eysenck. 1983a). Recently, extraversion has been directly associated with sensory reducing (Larsen \& Baggs, 1986) as well as with daily mood intensity (Larsen \& Diener, 1987).

In conclusion, the current studies suggest that emotional responses may function within an arousal regulation framework as predicted by reducer/augmenter theory. The rich nomological network surrounding reducer/augmenter theory and the cumulative nature of findings in this area suggest that the regulative role of emotional responses within an optimal stimulation or optimal arousal framework deserves further research.

Acknowledgements - This research was supported in part by grant number ROI MH42057 and Research Scientist Development Award number KO1 MH00704 from the National Institute of Mental Health to Randy J. Larsen. 


\section{REFERENCES}

Baker, A. H., Mishara, B. L., Kostin, I. W. \& Parker, L. (1976). Kinesthetic affereffect and personality: A case study of issues involved in construct validity. Journal of Personality and Social Psychology, 34, 1-13.

Baker, A. H., Mishara, B. L., Kostin, I. W. \& Parker, L. (1979). Menstrual cycle affects kinesthetic aftereffect, an index of personality and perceptual style. Journal of Personality and Social Psychology, 37, 234-246.

Barnes, G. E. (1976). Individual differences in perceptual reactance: A review of the stimulus intensity modulation individual difference dimension. Canadian Psychological Review, 17, 29-52.

Barnes, G. E. (1985). The Vando R-A scale as a measure of stimulus reducing-augmenting. In Strelau, J., Farley, F. H. \& Gale, A. (Eds), The biological basis of personality and behavior (Vol. 1, pp. 171-180). Washington, D.C.: Hemisphere.

Buchsbaum, M. S. \& Pfefferbaum, A. (1971). Individual differences in stimulus intensity response. Psychophysiology, 8, 600-611.

Buchsbaum, M. S., Hair, R. J. \& Johnson, J. (1983). Augmenting and reducing: Individual differences in evoked potentials. In Gale, A. \& Edwards, J. A. (Eds), Physiological correlates of human behavior. Vol. III: Individual differences and psychopathology (pp. 117-138). New York: Academic Press.

Crowne, E. P. \& Marlowe, D. (1964). The approval motive. New York: Wiley.

Davis, C., Cowles, M. \& Kohn, P. (1983). Strength of the nervous system and augmenting-reducing: Paradox lost. Personality and Individual Differences, 5, 491-498.

Deaux, E. (1976). A psychophysiological influence on the choice of illicit drugs. Physiological Psychology, 4, $400-404$.

Derryberry, D. \& Rothbart, M. K. (1984). Emotion, attention, and temperament. In Izard, C. E., Kagan, J. \& Zajonc, R. R. (Eds), Emotion, cognition, and behavior (pp. 132-166). New York: Cambridge University Press.

Diener, E. \& Larsen, R. J. (1984). Temporal stability and cross-situational consistency of affective, cognitive, and behavioral responses. Journal of Personality and Social Psychology, 47, 871-883.

Dunivin, D. \& Zenhausern, R. (1981). Differential hemispheric activation and hysterical and obsessive personality styles. Bulletin of the Psychonomic Society, 17, 23-25.

Eysenck, H. J. (1967). The biological basis of personality. Springfield, Ill.: Thomas.

Eysenck, H. J. (1983a). Psychophysiology and personality: Extraversion, neuroticism, and psychoticism. In Gale, A. \& Edwards, J. A. (Eds), Physiological correlates of human behavior, Vol. III: Individual differences and psychopathology (pp. 13-30). New York: Academic Press.

Eysenck, M. W. (1983b). Problems with the arousal construct. Paper presented to the annual meeting of the Psychophysiology Society, London.

Geen, R. G. (1984). Preferred stimulation levels in introverts and extraverts: Effects on arousal and performance. Journal of Personality and Social Psychology, 46, 1303-1312.

Goldman, D., Kohn, P. M. \& Hunt, R. W. (1983). Sensation seeking, augmenting-reducing, and absolute auditory threshold: A strength of the nervous system perspective. Journal of Personality and Social Psychology, 45, 405-411.

Herzog, T. T. \& Weintraub, D. J. (1982). Roundup time at personality ranch: Branding the elusive augmenters and reducers. Journal of Personality and Social Psychology, 42, 729-737.

Herzog, T. R., Williams, D. M. \& Weintraub, D. J. (1985). Meanwhile, back at personality ranch: The augmenters and reducers ride again. Journal of Personality and Social Psychology, 48, 1342-1352.

Kohn, P. M., Barnes, G. E. \& Hoffman, F. M. (1979). Drug-use history and experience seeking among adult male correctional inmates. Journal of Personality and Social Psychology, 47, 708-715.

Knorring, L. von \& Johansson, F. (1980). Changes in the augmenter-reducer tendency and in pain measures as a result of treatment with a serotonin-reuptake inhibitor-Zimelidine. Neuropsychobiology, 6, 313-318.

Larsen, R. J. (1987). The stability of mood variability: A spectral analytic approach to daily mood assessments. Journal of Personality and Social Psychology, 52, 1195-1204.

Larsen, R. J. \& Baggs, D. (1986). Some psychophysical and personality correlates of the Strelau Temperament Inventory. Personality and Individual Differences, 7, 561-565.

Larsen, R. J. \& Diener, E. (1985). A multitrait-multimethod examination of affect structure: Hedonic level and emotional intensity. Personality and Individual Differences, 6, 631-636.

Larsen, R. J. \& Diener, E. (1987). Affect intensity as an individual difference characteristic: A review. Journal of Research in Personality, 21, 1-39.

Larsen, R. J., Diener, E. \& Cropanzano, R. (1987). Cognitive operations associated with individual differences in affect intensity. Journal of Personality and Social Psychology, 53, 767-774.

Ludwig, A. M., Cain, R. B. \& Wikler, A. (1977). Stimulus intensity modulation and alcohol consumption. Journal of Studies in Alcohol, 238, 2049-2056.

Mishara, B. L. \& Baker, A. H. (1978). Kinesthetic aftereffect scores are reliable. Applied Psychological Measurement, 2, 239-247.

Mishara, B. L. \& Baker, A. H. (1981). Individual differences in old age: The stimulus intensity modulation approach. In Kastenbaum, R. (Ed.), Old age on the new scene (pp. 160-167). New York: Springer.

Petrie, A. (1967). Individuality in pain and suffering. Chicago: University of Chicago Press.

Petrie, A., Collins. W. \& Solomon, P. (1958). Pain sensitivity, sensory deprivation, and susceptibility to satiation. Science, $128,1431-1433$.

Robertson, R. J., Gillespie, R. L., Hiatt, E. \& Rose, K. D. (1977). Perceived exertion and stimulus intensity modulation. Perceptual and Motor Skills, 45, 211-218.

Ryan, E. \& Foster, R. (1967). Athletic participation and perceptual augmentation and reduction. Journal of Personality and Social Psychology, 6, 472-476.

Sales, S. M. (1971). Need for stimulation as a factor in social behavior. Journal of Personality and Social Psychology, 19, $124-134$.

Sales, S. M. (1972). Need for stimulation as a factor in preferences for different stimuli. Journal of Personality Assessment, $36,55-61$.

Sales, S. M. \& Throop, W. F. (1972). Relationship between kinesthetic aftereffects and 'strength of the nervous system'. Psychophysiology, 9, 492-497. 
Sales, S. M., Guydosh, R. M. \& Iacono, W. (1974). Relationship between 'strength of the nervous system' and the need for stimulation. Journal of Personality and Social Psychology, 29, 16-22.

Schooler, C., Buchsbaum, M. S. \& Carpenter, W. T. (1976). Evoked response and kinesthetic measures of augmenting/reducing in schizophrenics: Replications and extensions. Journal of Nervous and Mental Disease, 163, $221-232$.

Shapiro, D. (1965). Neurotic styles. New York: Basic Books.

Silverman, J., Buchsbaum, M. S. \& Henkin, R. (1969). Stimulus sensitivity and stimulus intensity control. Perceptual and Motor Skills, 28, 71-78.

Strelau, J. (1982). Biologically determined dimensions of personality or temperament? Personality and Individual Differences. $13,355-360$.

Strelau, J. (1983). Temperament, personality, activity. New York: Academic Press.

Strelau, J. (1987). Personality dimensions based on arousal theories: Search for integration. In Strelau, J. \& Eysenck, H. J. (Eds), Personality and arousal (pp. 269-284). New York: Plenum Press.

Tucker, D. M. \& Williamson, P. A. (1984). Asymmetric neural control systems in human self-regulation. Psychological Review, 91, 185-215.

Vando, A. (1969). A personality dimension related to pain tolerance. Unpublished doctoral dissertation. New York: Columbia University.

Zentall, S. S. \& Zentall, T. R. (1983). Optimal stimulation: A model of disordered activity and performance in normal and deviant children. Psychological Bulletin, 94, 466-471.

Zuckerman, M. (1987). A critical look at three arousal constructs in personality theories: Optimal levels of arousal, strength of the nervous system, and sensitivities to signals of reward and punishment. In Strelau, J. \& Eysenck, H. J. (Eds), Personality and arousal (pp. 217-232). New York: Plenum Press. 